\title{
Only and focus in Imbabura Quichua
}

\author{
Jos TELLINGS \\ University of California, Los Angeles*
}

\section{Introduction}

This paper investigates the interaction of focus and the exclusive particle -lla 'only' in Imbabura Quichua. Imbabura Quichua (henceforth Quichua) ${ }^{1}$ is a Quechuan language spoken in Imbabura Province in Northern Ecuador. Quichua is a highly agglutinative, suffixing language with a predominantly verb-final word order. A 2008 estimate of the number of speakers is 150,000 (Gómez-Rendón 2008:182fn.). Existing literature on this language includes one descriptive grammar (Cole 1982), whereas most theoretical work on this language is directed towards (morpho)syntax (Cole and Hermon 1981; Hermon 2001; Willgohs and Farrell 2009), and its evidential system (to be discussed in section 2.2 below) (see Sánchez 2010:236ff. for a more exhaustive bibliography on the Quechuan languages).

The study of focus in Quichua is worthwhile for a number of reasons. First, as I will discuss in a little more detail in section 2.1 below, Quichua is a relatively uncommon language from a point of view of focus typology, because it realizes focus non-phonologically, and it has a bound morpheme exclusive particle -lla. The semantic study of focus is still dominated by English and other languages that realize focus by phonological means. Studying a typologically marked language will be insightful in testing our theory for cross-linguistic validity.

Second, this work contributes to an existing body of research on the suffix $-m i$ which appears in several Quechuan languages, and which belongs to perhaps the best studied parts of the Quechuan language family. The suffix is generally assumed to be an evidential marker that doubles as a focus marker, although to my knowledge there have been no previous studies of its use as a focus marker in relation with particles such as 'only' or 'also'. In section 3, I will show that the suffix -mi does not in general mark the argument of -lla, showing that Quichua displays non-uniform focus marking. This leads to questions about focus marking strategies in Quichua, as well as more theoretical questions about how different conceptions of focus are related: the introduction of alternatives and the marking of new information seem to be formally distinguished in Quichua, while theoretical proposals based on English

*My many thanks go to my wonderful consultant Emilia Chuquín, for her continuous patience, enthusiasm and interest in this project. I also want to thank the members of the UCLA 2012-2013 Field Methods class. I thank Pam Munro, Sarah Murray and Jessica Rett for their very helpful comments and suggestions during several stages of this work. Finally, I thank the audiences of the UCLA American Indian seminar and BLS 40 for their valuable comments and input.

${ }^{1}$ I will use the name (Imbabura) Quichua to refer to the language under investigation, and the more common name Quechua to refer to the Quechuan language family in general. The reason for this is that the Northern Quechuan languages have lost the [e] and [o] morphemes from Proto-Quechua, which the (more widely studied) Southern Quechuan languages have retained (Peter Landerman, p.c.; cf. Gómez-Rendón 2008:169fn.). Quichua (Kichwa, [kitfwa]) is also one of the names Imbabura Quichua speakers use for their language. 
have attempted to reduce these two to a common basis. In addition, the conceptual link between focus and evidentiality that the dual role of $-m i$ has been taken to illustrate, may now have to be reconsidered.

Most of the conclusions I reach for -lla also hold for the additive particle -pash 'also/too'. For reasons of space and simplicity I will restrict my attention to -lla. An additional reason to study -lla (as opposed to -pash) is that it aids the understanding and exploration of intensifiers (also known as emphatic reflexives, e.g. 'The queen herself'): these are expressed in Quichua by the suffix combination -lla-taj. Intensifiers form another category of expressions that are traditionally thought to interact with focus, and a better understanding of the behavior of -lla will shed light on its surprising appearance in this construction (see Tellings 2014b).

The layout of the paper is as follows. Section 2 discusses cross-linguistic variation with respect to focus realization, and for Quichua in particular, and also reviews earlier work on - $m i$ in various Quechuan languages. Section 3 is the main theoretical part of the paper, and studies the interaction of $-l l a$ with $-m i$ in detail. I conclude that although $-m i$ has certain focus uses, the exclusive particle does not always co-occur with it. Instead I propose a theory of structural association, in which the morphological connection between -lla and the stem it attaches to plays the role that association-by-focus does in English (section 3.3).

Section 4 explores some unreported facts about the morphosyntax of -lla when it applies to non-nominal arguments. Here we find some surprising paradigms of reduplication, which are reminiscent of verb doubling focus strategies in African languages. Besides these descriptive facts, I show that reduplication, when not used in combination with -lla, can also be used in cases of contrastive focus, which further refines our view of focus marking in Quichua. I will argue that the reduplication strategies are additional instances of structural association, maintaining a uniform analysis of -lla.

One terminological note is in order before we start. Because the interaction of focus with the particle -lla is part of the research question, I will refrain from using the common term 'focus-sensitive particle' for it, and instead use the more neutral term 'alternative-sensitive particle' (AS-particle), which I borrow from Hartmann and Zimmermann's (2008) work on focus in an African language that in some respects is similar to Quichua (to be discussed further in section 3.3).

Unless otherwise noted, all reported data come from fieldwork with a native speaker consultant (Barchas-Lichtenstein et al. 2013; Tellings 2014a).

\section{The marker $-m i$}

\subsection{Focus typology}

I take focus to be an information-structural notion, as is standard (e.g. Zimmermann and Onea 2011). Although a predominance of literature on English and related languages has made the term sound synonymous with the phonological cues of its realization in those languages, cross-linguistic work on focus has shown that focus and phonology should be kept separate. Languages differ with respect to how they express focus (called 'focus realization'). English and many other languages use a variety of phonological means for this 
purpose: different types of pitch accent, phonological phrasing, pitch range expansion (for tone languages; Sun-Ah Jun, p.c.). Other languages have a fixed syntactic position for focus, or use morphological means for marking focus, e.g. by employing a focus affix. This is the case for various African languages (Aboh et al. 2007), and also Quichua falls in this category.

The non-phonological focus realization of Quichua is an important point, which has been established earlier for other Quechuan languages (Muntendam 2012), and was confirmed in our current fieldwork (Barchas-Lichtenstein et al. 2013). It is also in line with the tendency of Quichua to use morphology where English uses prosodic means. For instance, the intonation pattern of questions and declarative sentences is the same (with the exception of echo questions). This was already discussed by Cole (1982), and confirmed by phonetic studies in the current fieldwork (Kim 2013; cf. Sánchez 2010 for Southern Quechua).

Besides focus realization, there is another dimension of cross-linguistic variation with respect to focus: the morphological form AS-particles take. König (1991) distinguishes between adverbial-type AS-particles and clitic-like or bound AS-particles. Adverbial type AS-particles, found in English, many other European languages, but also in Chinese, are free morphemes that typically enjoy a rather free position within the sentence, in particular in languages in which they associate with phonologically marked focus (such as English). The clitic / bound morpheme type is found for instance in Turkish (Göksel and Özsoy 2003), Japanese and Hindi (Otoguro 2003), Finnish and other languages (König 1991:18). Quichua also falls in the latter category, with -lla 'only' being a suffix. Also other ASparticles in Quichua such as -pash 'also' (which can also have a scalar use to mean 'even') are suffixes. A language that has exclusive particles that are bound morphemes is considered to be relatively rare cross-linguistically. König (1991:20) discusses a syntactic asymmetry by which many languages are of a 'mixed type' in having exclusive particles precede their focus as a free morpheme, but additive particles follow their focus as a clitic (Bengali is one such language). Only 4 out of 70 languages in König's (1991) study have bound exclusive AS-particles in addition to bound additive particles; one of these is Tarma Quechua (Central Peru). Elsewhere this has been claimed to be a property not only of Quechuan languages, but of Andean languages at large (Adelaar 2004:217).

The combination of these two properties, non-phonological focus marking, and bound exclusive AS-particles, make Quichua a typologically marked language when it comes to focus, and therefore makes a good case study to test the cross-linguistic validity of theoretical accounts of focus.

\subsection{Existing views on $-m i$}

The - $m i$ suffix has been widely studied in a variety of Quechuan languages, and has generally been assumed to be an evidential/validational marker that doubles as a focus marker (Jake and Chuquín 1979; Nuckolls 1993; Muysken 1995; Faller 2002, 2003; Gómez-Rendón 2006; Olbertz 2008; Sánchez 2010; Kwon 2012). Morphologically, -mi is classified as an 'independent suffix', meaning that it can attach to almost all syntactic categories: nouns, verbs, adjectives, numerals/quantifiers, etc. ${ }^{2}$ It always appears as the final suffix on a stem.

\footnotetext{
${ }^{2}$ Since Quichua is such a highly agglutinative language, there are not many free-standing functional items. The negation word mana 'not/no' is one of them, and we found that - mi cannot attach to it. Here Imbabura
} 
Most of the literature listed above has directed its attention exclusively or predominantly to the evidential use of $-m i$. These works propose that $-m i$ is either an evidential expressing direct evidence, or a validational marker expressing certainty (see Faller 2003 for the evidential/validational distinction, and a hybrid view). Those works that do address the focus marking role of $-m i$ restrict themselves to question-answer congruence (Kwon 2012:§4) or contrastive focus (Jake and Chuquín 1979:179; Kwon 2012:§4.3). I am not aware of any work on the relation between -mi and AS-particles, which is undertaken here.

In addition, some authors, who concentrate on evidentiality, and shun the empirical details of focus marking, note in passing that a conceptual relation between evidentiality and information structure is plausible, although the details of such a connection are not quite clear yet (Faller 2003:2; Speas 2008:949; Kwon 2012:§5.3). Very briefly, the general idea is that expressions with evidential marking tend to convey information that is new to the addressee. Whether explanations of the conceptual link between evidentiality and information structure along these lines have cross-linguistic validity is unclear; for instance it would make rather strong predictions for languages in which evidential marking is obligatory (as we will see, the use of $-m i$ and other evidentials is optional to some degree in Quichua).

In Imbabura Quichua, a clear use of $-m i$ as a focus marker can be found in question-answer pairs. In (1), I give data that confirm earlier findings about this role of -mi (Kwon 2012). A felicitous answer to subject question in (1a) has - mi on the subject Marya, irrespective of the word order $(1 \mathrm{~b}-\mathrm{c})$. The suffix cannot be omitted $(1 \mathrm{~d})$ or attached to another constituent $(1 \mathrm{e}) .^{3}$
a. A: Pitaj Pidrutaka rikurka?
A: Pi-taj Pidru-ta-ka riku-rka? who-Q Pedro-ACC-TOP see-PST
'Who saw Pedro?'
b. B: Pidrutaka Maryami rikurka.
B: Pidru-ta-ka Marya-mi riku-rka. Pedro-ACC-TOP Maria-MI see-PST
'Maria saw Pedro'
c. B': Marya-mi Pidru-ta-ka riku-rka. Maria-MI Pedro-ACC-TOP see-PST
d. \# B": Pidru-ta-ka Marya riku-rka. Pedro-ACC-TOP Maria see-PST
e. \# B'": Pidru-ta-mi Marya-ka riku-rka. Pedro-ACC-MI Maria-TOP see-TOP

This use of - $m i$ seems to be very robust: whereas in many other contexts and constructions, the use of -mi (e.g., as evidential marker) is optional and varies in position, in question-

Quichua differs from Cuzco Quechua (Faller 2002:12).

${ }^{3}$ The following abbreviations are used in glosses: 123 '1st/2nd/3d person', ACC 'accusative', ADD 'additive AS-particle', ADV 'adverbializer', CAUs 'causative', EXCL 'exclusive AS-particle', FM 'focus marker (Bura)', FUT 'future', IMP 'imperative', LIM 'limitative', LOC 'locative', MI = -mi suffix (discussed in text), NEG 'negation', NZR 'nominalizer', PL 'plural', PRES 'present', PROG 'progressive', PST 'past', Q 'question', SG 'singular', тOP 'topic'. 
answer pairs it consistently marks the questioned constituent, and is obligatorily present. Having (re-)established that - $m i$ functions as a focus marker in the typical case of questionanswer congruence, the question arises whether - $m i$ plays a similar role in another typical case of focus-sensitivity: the relation with AS-particles. After introducing the exclusive AS-particle -lla in section 3.1, I will look in detail at this question in section 3.2.

\section{The exclusive particle and $-m i$}

In this section I will introduce the exclusive AS-particle -lla with nominal associates (section 3.1) and discuss the relation between -lla and - $m i$ (section 3.2). In section 3.3, I present my proposal that -lla associates structurally with its argument, and discuss parallels between my proposal and existing work on AS-particles in the African language Bura (Hartmann and Zimmermann 2008, 2012).

\subsection{The distribution of the exclusive particle -lla}

The suffix -lla is often labelled a 'limitative suffix' in previous literature, which ought to reflect a wide set of uses the suffix has been shown to have, including the use as an exclusive particle, as a diminutive, indicating politeness, indicating precision, etc. (cf. Weber 1989:§19.1 for Huallaga Quechua). I will here concentrate on its use as an exclusive ASparticle, which I gloss as EXCL. In section 4, I will return to some of the other uses of -lla, and show that there are morphosyntactic reasons to keep the exclusive use of -lla separate from other 'limitative' uses.

This section is only concerned with the distribution of -lla when it has a DP associate. These cases are morphosyntactically most straightforward, and most illustrative for the theoretical conclusions I will reach. In section 4, I will discuss the different morphosyntactic strategies Quichua employs when -lla takes non-nominal complements, and I will argue that these data do not undermine my analysis.

In the canonical case when -lla takes a simple, unmodified noun in its semantic scope, -lla attaches to that noun. The sentences in (2) illustrate this: there is a direct match between the position of -lla and its semantic scope.

(2) a. Ñukanchika karamilukunataka wawakunamanllami karanchi.

Nukanchi-ka karamilu-kuna-ta-ka wawa-kuna-man-lla-mi kara-nchi.

we-TOP sweets-PL-ACC-TOP child-PL-LOC-EXCL-MI give-1PL

'We only give sweets to CHILDREN'

b. Karamilukunallatami wawakunamanga karanchi.

Karamilu-kuna-lla-ta-mi wawa-kuna-man-ga kara-nchi.

sweets-PL-EXCL-ACC-MI child-PL-LOC-TOP give-1PL

'We only give SWEETS to children'

This pattern is found consistently when the scope of -lla consists of a simple noun phrase. In section 4 , we will see that when a simplex verb, adjective or adverb is the semantic scope 
of -lla, a different morphosyntactic strategy is employed, but the position of -lla nevertheless corresponds to its scope.

The only case I found in which there is a scope mismatch, is that of complex noun phrases. When a noun is modified by an adjective, a relative phrase, a comitative adjunct or similar modifiers, the suffix -lla consistently attaches to the head noun. Such sentences are focally ambiguous: the semantic scope may either be the entire nominal constituent, or be restricted to the modifier. This is illustrated for adjectival modification in (3).

(3) Maryaka puka mansanallatami gushtan.

Marya-ka puka mansana-lla-ta-mi gushta-n.

Maria-TOP red apple-LIM-ACC-MI like-PRES

'Maria only likes [RED] apples' / 'Maria only likes [RED APPLES]'

Example (4) shows this more explicitly with a contrast. The first clauses of (4a) and (4b) are identical in structure, despite the difference in semantic scope of -lla.

(4) a. Jwanga mana birrdi mansanakunallata gushtanllu, payka puka mansanakunatapashmi gushtan.

Jwan-ga mana birrdi mansana-kuna-lla-ta gushta-n-llu, pay-ka puka

Juan-TOP not green apple-PL-EXCL-ACC like-PRES-NEG, he-TOP red

mansana-kuna-ta-pash-mi gushta-n.

apple-PL-ACC-ADD-MI like-PRES

'Juan does not only like GREEN apples, he also likes RED apples.

b. Jwanga mana puka mansanakunallata gushtanllu, payka puka ubaskunatapashmi gushtan.

Jwan-ga mana puka mansana-kuna-lla-ta gushta-n-llu, pay-ka puka

Juan-TOP not red apple-PL-EXCL-ACC like-PRES-NEG, he-TOP red ubas-kuna-ta-pash-mi gushta-n. grape-PL-ACC-ADD-MI like-PRES

'Juan does not only like red APPLES, he also likes red GRAPES.

An important observation is that other discourse particles in Quichua, such as - $m i$ and the topic marker $-k a$, have similar restrictions. It has been observed for other Quechuan languages that - $m i$ always attaches to the head noun ("constituent-external" in Muysken's (1995:380) terminology), and similarly for - $k a$ (Sánchez 2010:71). Example (5) replicates this finding for - $m i$ in Quichua: even though the questioned information is 'red', and 'apple' is old information, - $m i$ still attaches to mansana 'apple'.

(5) a. Q: Ima mansanatataj mikurkangi?

Q: Ima mansana-ta-taj miku-rka-ngi?

what apple-ACC-Q eat-PST-2SG

'What kind of apples did you eat?'

b. A: Puka mansanatami mikurkani.

A: Puka mansana-ta-mi miku-rka-ni. red apple-ACC-MI eat-PST-1SG 
'I ate RED apples'

c. $\quad *$ A: Pukami mansanata mikurkani.

A: Puka-mi mansana-ta miku-rka-ni. red-MI apple-ACC eat-PST-1SG

The following example similarly shows that $-k a$ cannot appear on a DP-internal modifier:

(6) a. Musa warmika dujturami.

Musa warmi-ka dujtura-mi.

young woman-TOP doctor-MI

'The young woman is a doctor'

b. * Musaka warmi dujturami.

Musa-ka warmi dujtura-mi.

young-TOP woman doctor-MI

In Sánchez's (2010) Minimalist syntactic account of focus/evidentiality marking in Southern Quechua, the - $m i$ and $-k a$ suffixes are the morphological spell-out of the checking of abstract focus/evidentiality and topic features, respectively. These features reside in functional heads Foc, Evid and Top in the left periphery. Sánchez suggests that these suffixes do not appear on DP-internal modifiers because of the "lack of a functionally rich periphery inside DPs" (Sánchez 2010:69). It seems unlikely to me that this theory can be extended straightforwardly to a parallel account for the distribution of -lla in Quichua, since a functional head corresponding to the exclusive particle 'only' is not typically assumed in functional hierarchies in the style of Cinque (1999). I leave the syntactic question of whether a parallel analysis of the distribution of $-m i,-k a$, and $-l l a$ is possible, to future research.

Also cross-linguistically, cases of focal underdetermination are not uncommon. A wellknown fact about English, for instance, is that focal projection results in ambiguity (e.g. Reinhart 2004). In (7), where boldface indicates neutral main stress, the focused constituent can the object DP, the VP or the TP, corresponding with the three different questions.

(7) A: Mary is eating pizza.

a. Q: What is happening?

b. Q: What is Mary doing?

c. Q: What is Mary eating?

In English such patterns have mainly been related to phonological properties such as neutral stress and focus projection, and similarly I believe that the instance of focal underdetermination in Quichua discussed in this section is more a matter of (morpho)syntax rather than of the semantics of AS-particles.

I will now proceed to discuss the relation between -lla and $-m i$ in detail.

\subsection{The relation between $-l l a$ and $-m i$}

The traditional idea is that the semantic role of focus is to introduce alternatives (e.g. Rooth 1992; cf. Zimmermann and Onea 2011). AS-particles such as 'only' and 'also' directly associate with these alternatives. A natural question, then, is whether the suffix - mi, which 
we saw functions as a focus marker in at least certain cases, is responsible for generating the alternatives that -lla associates with.

A first look at the data with -lla that we collected in our fieldwork corpus (BarchasLichtenstein et al. 2013) suggests that this might indeed be the case. Quantitatively, -llamarked words also bear the - $m i$ suffix in the majority of cases. Of course, numerical majority is meaningless unless the data are somehow controlled for sentence type. Indeed, in this section I will argue that a more careful look at the data leads to the conclusion that -llamarked words do not necessarily take - $m i$. I will now present four empirical arguments to support this claim, and subsequently I will look at these data from a more theoretical perspective. I will also offer an alternative explanation for the perceived wide-spread cooccurrence of -lla and $-m i$.

1. It is known from earlier work on - $m i$ that there are certain restrictions on its distribution, findings which I have replicated in my fieldwork. The suffix - $m i$ is not licensed in imperatives (Muysken 1995:382; Faller 2002:266; Sánchez 2010:60ff.), inside the body of a question, ${ }^{4}$ or inside the scope of negation (Jake and Chuquín 1979:173; Faller 2002:227ff.). In (8) below I present novel data that show that, first, -lla may occur inside these contexts, and second, that when it does it cannot combine with -mi.

a. Yuraj sadakunallata $(* m i)$ agllay.

Yuraj sada-kuna-lla-ta- $\left({ }^{*}\right.$ mi $)$ aglla-y.

white corn-PL-EXCL-ACC- $\left({ }^{*} \mathrm{MI}\right)$ select-IMP

'Select only the white corn.'

b. Pitaj arrusllata $\left\{\mathrm{ka} /{ }^{*}\right.$ mi $\}$ mikurka?

[question]

Pi-taj arrus-lla-ta- $\left\{\mathrm{ka} /{ }^{*} \mathrm{mi}\right\}$ miku-rka?

who-Q rice-EXCL-ACC-TOP $/{ }^{*}$ MI eat-PST?

'Who ate only rice?'

c. Mana Maryalla $(*$ mi) puñujunllu.

[wide-scope negation]

Mana Marya-lla- $\left({ }^{*}\right.$ mi $)$ puñu-ju-n-llu.

not Maria-EXCL- $\left({ }^{*}\right.$ MI $)$ sleep-PROG-PRES-NEG

'Not only Maria is sleeping'

d. Maryallami mana puñujun.

[narrow-scope negation]

Marya-lla-mi mana puñu-ju-n.

Maria-EXCL-MI not sleep-PROG-PRES

'Only Maria is not sleeping'

Examples (8cd) form a minimal pair that shows the behavior of $-m i$ with respect to the scope of negation. Since the interpretation of -lla in the sentences in (8) is not different from -lla in environments in which - $m i$ is licensed, and still involves alternatives, this provides a strong argument for my claim that $-m i$ is not responsible for introducing alternatives.

\footnotetext{
${ }^{4}$ The $w h$-word or a pied-piped constituent may bear -mi (cf. Cole 1982:18; cf. Olbertz 2008:115), but -mi never occurs on other constituents in the body of the question.
} 
2. In answers to questions that contain -lla, - $m i$ attaches to the constituent corresponding to the novel information, not to -lla.

(9) Pitaj arrusllataka mikurka?

Pi-taj arrus-lla-ta-ka miku-rka?

who-Q rice-EXCL-ACC-TOP eat-PST?

'Who ate only rice?'

a. Jwanmi arrusllataka mikurka.

Jwan-mi arrus-lla-ta-ka miku-rka.

Juan-MI rice-EXCL-ACC-TOP eat-PST

'JUAN ate only rice.'

b. \# Jwanga arrusllatami mikurka.

Jwan-ga arrus-lla-ta-mi miku-rka.

John-TOP rice-EXCL-ACC-MI eat-PST

'Juan ate only rice' [fine in other contexts, but inappropriate as an answer to this question]

Reasoning by contradiction, let us assume that we expect -lla-marked words to also be marked with - $m i$. Then these data are at some level similar to cases of secondoccurrence focus in English, in which two focus-sensitive operators occur in one sentence, but only one element in the sentence appears to be phonologically marked for focus:

\section{(10) A: John only kissed MARY.}

B: Yes, even BILL only kissed [Mary $]_{\mathrm{SOF}}$.

The traditional view on these examples is that 'Bill' is phonologically focus-marked (by virtue of being an argument of the particle 'even'), but 'Mary' in (10B) is not phonologically marked (indicated by soF 'second-occurrence focus'), even though it is the argument of the focus-sensitive operator 'only'. However, recent phonetic work (Beaver et al. 2007) suggests that second-occurrence focus in fact comes with certain phonetic cues that may not be directly noticeable to the informal listener, but listeners are still sensitive to.

The situation in Quichua in (9) is similar in that, by hypothesis, we have two constituents that need to be marked by - mi: the questioned constituent, in this case Jwan 'Juan', and the -lla-marked constituent. It is well known throughout the Quechua literature on - $m i$ that the suffix may occur only once per clause (e.g. Jake and Chuquín 1979:173, Cole 1982:165, Muysken 1995:381, Sánchez 2010:60). One theory that predicts the position of $-m i$ in the case of multiple (potential) hosts is due to Sánchez (2010). Her proposal is that only the host closest to the Focus head in the left periphery is morphologically marked (p. 62ff.). The data in (9) seem to corroborate this theory as the - $m i$ suffix attaches to the highest ('leftmost') element in the sentence. However, the crucial observation is that the -lla-marked constituent here takes the 
topic marker $-k a$. It is well known that the $-k a$ marker is in complementary distribution with $-m i$ in the sense that the two can never co-occur on the same stem $\left({ }^{*} X-m i-k a\right.$, *X-ka-mi). Therefore Sánchez's theory would predict no further (discourse) markers to attach to the -lla-marked constituent, and does not explain the appearance of - $k a$. It is not clear to me how other theories that predict the single spell-out of $-m i$ with multiple hosts could explain this pattern either. Therefore, I cancel the earlier hypothesis, and conclude that the -lla-marked constituent is not necessarily marked by $-m i$. Instead, these data suggest that when -lla in other contexts does appear with -mi,-mi plays a different role, presumably evidential, and does not introduce alternatives.

3. There are some cases in which a -lla-marked constituent is optionally marked by $-m i$. The precise distribution of cases in which $-m i$ is optional is not quite clear yet, but this general finding is in line with earlier observations about the optionality of $-m i$ (e.g. Olbertz 2008).

Jwanga alkullata(mi) misillata(mi) rikurka.

Jwan-ga alku-lla-ta-(mi) misi-lla-ta-(mi) riku-rka.

Juan-TOP dog-EXCL-ACC-(MI) cat-EXCL-ACC-(MI) see-PST

'Juan saw only the dog and the cat' [either - $m i$ on both conjuncts or on neither]

(12) Chay musuka kandami wakachiyllata(mi) wakachinga. $^{5}$

Chay musu-ka kan-da-mi waka-chi-y-lla-ta-(mi) waka-chi-nga.

that boy-TOP you-ACC-MI cry-CAUS-NZR-LIM-ACC-(MI) cry-CAUS-FUT

'That boy will only make you cry'

4. We find that other evidential/validational markers may combine with -lla: ${ }^{6}$ the certainty marker -mari, the conjectural -shi and the doubt marker -chari may all combine with -lla.

a. Pidruka aychallatamari mikurka.

Pidru-ka aycha-lla-ta-mari miku-rka.

Pedro-TOP meat-EXCL-ACC-CERTAIN eat-PST

'Pedro for sure ate only meat'

b. Jwanllashi fishtamanga shamurka.

Jwan-lla-shi fishta-man-ga shamu-rka.

Juan-EXCL-CONJECTURE party-LOC-TOP come-PST

'I suppose only Juan came to the party'

c. Pidruka aychallatachari mikurka.

${ }^{5}$ This example involves verbal reduplication as a strategy of -lla-marking. This will be discussed further in section 4.2 .

${ }^{6} \mathrm{I}$ am indebted to Sarah Murray (p.c.) for the suggestion to elicit such data. 


\author{
Pidru-ka aycha-lla-ta-chari miku-rka. \\ Pedro-TOP meat-EXCL-ACC-DOUBT eat-PST \\ 'Pedro ate only meat (I wonder)'
}

The markers -mari, -chari and -shi are evidentials with a more specific meaning, that are not taken to double as focus markers. This suggests again that when -lla occurs with $-m i$, it is because of the evidential role of $-m i$, and not its (alleged) focus marker use.

Taking stock, by looking at more carefully controlled data, we saw that constituents with the -lla suffix do not necessarily also bear the $-m i$ suffix. Because in these contexts in which the -lla-marked constituent is not marked by - $m i$, the -lla suffix is still interpreted as an exclusive AS-particle meaning 'only X', the alternatives needed for its interpretation cannot be provided by - $m i$ but must come from a different source. Although one could in principle argue that in occurrences of $-l l a-m i$, the $-m i$ suffix does introduce alternatives for the interpretation of -lla, this posits two different grammatical strategies for the introduction of alternatives, which by Ockham's razor is unappealing. Furthermore, we have seen good reasons to believe that in occurrences of $-l l a-m i$, the $-m i$ plays the role of a (purely) evidential marker, e.g. as in (13) above.

Having established that - $m i$ does not introduce the alternatives the AS-particle applies to, I consequently believe that the perceived abundance of -lla-mi mentioned earlier is not the result of a grammatical dependency between the two morphemes, but can be explained in different terms. It seems plausible that in many neutral contexts 'only X' corresponds to new information in the sentence, and I propose that this is why in neutral contexts we see -lla and -mi so often together on the same constituent. In constructed contexts in which 'only $\mathrm{X}$ ' is instead part of the backgrounded information, as in (9), we see no presence of - $m i$ on the -lla-marked constituent, as expected. Furthermore, the presence of - $m i$ is very common in our fieldwork corpus at large (not just the -lla-data): in most simple, neutral contexts, the suffix - $m i$ appears somewhere in the sentence (for examples in this paper, see for instance simple sentences as in (20) and (21a) below). The many occurrences of -lla-mi can be considered as a consequence of the overall tendency.

\title{
3.3 Structural association
}

I will now discuss the consequences of the lack of a grammatical relation between -lla and $-m i$ for the theory of AS-particles. A common view takes 'only' to be a quantifying expression (see e.g. Herburger 2000, much of the following discussion is also based on Beaver et al.'s 2007 introduction), thus having two arguments corresponding to the semantic scope of 'only' and the VP-predicate (I set aside here the adjectival use of 'only').

$$
\begin{array}{lll}
\text { Only } & {[\text { Linda }]_{\mathrm{F}}} & {[\text { invited Bill to the party]. }} \\
& \text { semantic scope } & \text { predicate }
\end{array}
$$

The F-marking denotes a formal syntactic representation of focus, unrelated to how focus is realized (in English, the word would be pitch accented). Beaver et al. (2007) argue that 'only' is focus-sensitive because it selects one of its arguments (its semantic scope) by F-marking 
it, in English reflected by phonological marking. Argument selection by F-marking is taken to be an alternative strategy besides more common strategies of argument selection, such as morphology (e.g. case marking) and syntactic configuration (word order). Note that in this respect Beaver et al.'s approach is English-centered: they take F-marking to be closely related to phonological marking (p. 252). As a strategy of argument selection, F-marking is only distinct in its surface realization from morphological and configurational strategies in languages with phonological focus realization. In languages that have morphological or syntactic focus realization, F-marking would reduce to one of the two other strategies. Beaver et al. (2007:249), concentrating on English, state that the puzzle of focus sensitivity lies mainly in the link between phonology and the semantics/syntax of argument selection of focus-sensitive operators, while I would claim that in Quichua, the main puzzle about focus sensitivity lies in the link between the generation of alternatives and the syntax/semantics of the alternative-sensitive particle.

The discussion in section 3.1 made clear that, other than in English, Quichua does have a morphological structure available to link -lla with its argument, since in most cases there is a direct match between the position of -lla and its semantic argument. The only exception was formed by complex noun phrases, where -lla always attaches to the head noun.

We have also seen that there is clear empirical evidence to dismiss the idea that -llamarked constituents are always marked with $-m i$, rendering untenable the idea that this may be an explanation for how -lla selects its argument. This in turn led to the conclusion that -mi does not play the role of introducing alternatives.

I therefore propose that the exclusive AS-particle -lla in Quichua does not associate with its argument by focus via marking of $-m i$, but rather associates with its semantic scope structurally via the process of suffixation. A similar idea has been proposed for AS-particles in the African language Bura (Chadic) in work by Hartmann and Zimmermann (2008, 2012). A common property of many African languages is that they have two different strategies for focus-marking: the focus constituent may be fronted (ex-situ marking) or may stay in its base position (in-situ marking) (see Aboh et al. 2007 for an overview).

It has been reported for certain languages that in-situ focus marking is not marked phonologically (Hartmann and Zimmermann 2007, 2008 for Hausa and Bura, respectively). Furthermore, Bura has a focus marker an that only occurs with ex-situ focus, meaning that in-situ focus is completely unmarked (morphologically, phonologically and syntactically), suggesting that the interpretation of the information-structural content of focus must be determined purely pragmatically (Hartmann and Zimmermann 2012:1076fn. for Bura, and 2007:243 for Hausa).

The exclusive particle daci 'only' in Bura may either occur directly adjacent to its scope, or at a distance. Crucially, when daci is non-adjacent, its scope must be marked by the focus marker an, as the following example from Hartmann and Zimmermann (2008:201) illustrates:

a. Mtaku liha Biu daci.

[Bura]

Mtaku liha Biu daci.

Mtaku go Biu only

'Mtaku went only to BIU';

f 'Only MTAKU went to Biu' 
b. Mtaku an liha Biu daci.

[Bura]

Mtaku an liha Biu daci.

Mtaku FM go Biu only.

'Only MTAKU went to Biu'

Hartmann and Zimmermann (2008:202) argue that argument selection of daci in Bura either occurs by morphological focus marking with an (possibly at a distance), or structurally by daci being adjacent to its associate.

I propose that Quichua -lla has a structural association strategy similar to Bura daci with in-situ focus. I have reviewed empirical and conceptual arguments for this type of account. The finding of focal underdetermination in complex DPs does not constitute a problem for my account. We saw that the attachment of -lla to maximal projections parallels the behavior of $-m i$ and $-k a$, suggesting that it may be related to an independent syntactic property of Quichua. The focal ambiguity that is a result of this (exemplified in (3)) can be explained by filling in details about how alternatives are generated: when -lla attaches to a maximal DP projection, alternatives are generated for all subconstituents of the nominal phrase. This has been suggested for other languages such as Turkish (cf. Göksel and Özsoy 2003), and is not substantially different from theories of focus projection in English alluded to in section 3.1 above.

This concludes the first part of the paper. I now turn to cases in which the scope of -lla is a non-nominal constituent. Here, Quichua employs different morphosyntactic strategies, namely reduplication. Besides the purely empirical interest of this construction, I will show how other, non-AS readings of -lla come into the picture. I will also relate the data to verb doubling focus strategies in African languages, and furthermore show that these reduplicative strategies have an additional contrastive focus use, leading us to rethink our idea of 'nonuniform focus marking'. As far as I am aware, none of these facts have been reported before in the Quechua literature. The novel observations will still be in line with my proposal: I will argue that these are different types of structural association of -lla.

\section{Non-nominal associates}

\subsection{Adjectives and adverbs}

In example (3) we saw that -lla attaches to the head noun of an adjectivally modified noun phrase, even if the semantic scope of -lla is confined to just the adjective. It turns out that it is also grammatical to attach -lla directly to the adjective, as in (16), but this gives a different, non-AS reading.

(16) Maryaka pukalla mansanatami gushtan.

Marya-ka puka-lla mansana-ta-mi gushta-n.

Maria-TOP red-LIM apple-ACC-MI like-PRES

'Maria likes reddish/somewhat red apples'

f 'Maria only likes RED apples' 
The effect -lla has when attached to an adjective is that it expresses that the modified noun instantiates the quality expressed by the adjective to a lesser degree. In (16) this is translated by 'reddish' or 'somewhat red'. This use of -lla is productive for other gradable adjectives in Quichua (e.g. kushi 'happy'; kushi-lla 'somewhat happy').

This meaning of -lla corresponds better to its categorization as a 'limitative suffix' mentioned in section 3.1. Therefore in (16), I glossed -lla as a limitative marker (LIM), as opposed to an exclusive marker (EXCL) in all previous examples. Although presumably related, I think it is good to keep the use of -lla as an exclusive AS-particle and other uses of -lla separate: not only does a difference in alternative-sensitivity seem to be too important to reduce to mere polysemy, in particular the morphosyntactic differences reported here suggest a systematic distinction.

The crucial question at this point is how Quichua expresses a bare adjective (or AP) as an argument of -lla when used as an exclusive AS-particle. In this case we find adjectival reduplication, as illustrated in (17) and (18). In (17) the semantic scope of -lla is the adjective llaki 'sad'. This adjective is reduplicated, and -lla attaches to the first copy.

(17) Maryaka llakillami llaki, mana ungushkachu.

Marya-ka llaki-lla-mi llaki, mana ungushka-chu.

Maria-TOP sad-EXCL-MI sad, not ill-NEG

'Maria is only sad, not ill'

Example (18) shows this once more, and in addition shows that the same paradigm is observed for the additive AS-particle -pash.

(18) Kay bandiraka pukami killupash killumi. Chay bandiraka pukallami puka.

Kay bandira-ka puka-mi killu-pash killu-mi. Chay bandira-ka puka-lla-mi this flag-TOP red-MI yellow-ADD yellow-MI that flag-TOP red-EXCL-MI puka.

red

'This flag is red and yellow. That flag is only red'

Adverbs show the same pattern. Adverbs in Quichua may be derived from adjectives using a $-t a$ suffix (homophonous with the accusative case marker). Example (19a) shows the limitative meaning of -lla, (19b) shows the reduplication strategy, and (19c) illustrates that the adverbializing suffix cannot be reduplicated.

(19) a. Wawaka sinchillatami wakan.

Wawa-ka sinchi-lla-ta-mi waka-n.

baby-TOP loud-LIM-ADV-MI cry-PRES

'The baby cries somewhat loudly'

b. Wawaka sinchillatami sinchi wakan.

Wawa-ka sinchi-lla-ta-mi sinchi waka-n.

baby-TOP loud-EXCL-ADV-MI loud cry-PRES

'The baby cries only loudly' 


\section{c. * Wawaka sinchillatami sinchita wakan. \\ Wawa-ka sinchi-lla-ta-mi sinchi-ta waka-n. \\ baby-TOP loud-EXCL-ADV-MI loud-ADV cry-PRES}

Adjectival reduplication is not restricted to the combination with -lla as shown here, but is used productively in Quichua to expresses intensification of the adjective, as illustrated in $(20)$.

(20) Pidruka jatun-jatunmi.

Pidru-ka jatun-jatun-mi.

Pedro-TOP tall-tall-MI

'Pedro is very tall'

An important difference between (17) and (20) is the position of - $m i$ : in (17) it attaches to the first copy, whereas in (20) it attaches to the second copy. ${ }^{7}$ It turns out that attaching $-m i$ to the first copy in (17) is also possible, but only in contrastive contexts. It is infelicitous in out of the blue contexts. Example (21) shows such a contrastive context. Crucially, adjectival reduplication here does not mean intensification.

a. A: Pidruka kutsimi purin.

A: Pidru-ka kutsi-mi puri-n. Pedro-TOP fast-MI walk-PRES

'Pedro walks fast'

b. B: Mana, Pidruka alimandami (alimanda) purin.

B: Mana, Pidru-ka alimanda-mi (alimanda) puri-n. no, Pedro-TOP slow-Mi (slow) walk-PRES

'No, Pedro walks slowly' $\neq$ 'No, Pedro walks very slowly'

It is important to note that adjectival reduplication is not the only way to express contrastive focus. As indicated by the parentheses in (21b), simple attachment of - $m i$ to the adjective is also possible (the consultant suggested that adjectival reduplication is a more emphatic way to express a contrast). This also holds for question-answer pairs in which the adjective corresponds to the questioned constituent.

The examples in (20) and (21) show two different types of adjectival reduplication in Quichua. At the surface they look very similar, and they also share certain syntactic properties. For example neither in reduplication with the meaning of intensification, nor in reduplication in combination with -lla or contrastive focus, may any material (e.g. negation particles, adverbs) intervene between the reduplicated copies. However, the two types of reduplication can be distinguished by the position of suffix attachment. The first type carries the meaning of intensification (as in (20)), and suffixes attach to the second copy (this not only holds for - mi, but also for other suffixes; e.g. 'very loudly' is expressed as sinchi

\footnotetext{
${ }^{7}$ This is apparently different for -pash in (18). I leave such differences between -lla and -pash for future
} research. 
sinchi-ta). The second type is used both in combination with exclusive -lla (as in (17)), and for contrastive focus (as in (21)). For this type, suffixes attach to the first reduplicated copy.

The availability of reduplication for contrastive focus (which, again, does not have the meaning of intensification) suggests a morphosyntactic link between contrastive focus and exclusive AS-particles. In section 3 we concluded that Quichua displays non-uniform focus marking in the sense that focus in question-answer pairs and contrastive focus are expressed by the suffix - $m i$, while the argument of the exclusive AS-particle -lla need not marked by -mi. Here, however, by looking in more detail at adjectives, we have also found a commonality between the two types of focus: both use a special morphosyntactic construction of reduplication.

This brings us back to my proposal of structural association of exclusive -lla. I will assume that the reduplication strategy for exclusive -lla-attachment to adjectives is a different type of structural association, possibly influenced to the polysemy of the suffix in the adjectival domain. Alternatives are generated on attachment of -lla to the reduplicated phrase [ Adj Adj ].

\subsection{Verbs}

A similar situation holds for verbs. When -lla attaches directly to a verb, it has a meaning that is distinct from its normal exclusive particle use. This reading is not directly translatable into English, but judging from the contexts the consultant gave, it may paraphrasable by 'just' (in its non-temporal meaning) or 'easily'. I provide two examples below:

(22) Maryaka brinkarkallami.

Marya-ka brinka-rka-lla-mi.

Maria-TOP jump-PST-LIM-MI

'Maria just jumped' [context: Maria is a little girl, she didn't ask, she just jumped.]

Maryaka chakata yalirkallami.

Marya-ka chaka-ta yali-rka-lla-mi.

Marya-TOP bridge-ACC pass-PST-LIM-MI

'Maria just crossed the bridge' [context: the bridge is known to be a very dangerous bridge, but Maria is not aware of this, and she just crossed it (non-temporal 'just').]

Although some analyses of English 'just' classify it as a focus-sensitive particle (e.g. König $1991: \S 5.3)$, it is not clear that we can count this use of -lla on verbs as alternative-sensitive, given that 'just' in (22-23) is only an approximate translation. This requires further research, but for now I assume, based also on the intuitions of the consultant, that there is a clear distinction between the meaning of -lla in (22) and (23) on the one hand, and the cases of verbal reduplication to be discussed below on the other.

Quichua again employs a special construction in order to have a verb in the scope of the exclusive particle: - lla attaches to a nominalized copy of the verb. The verbal copy also carries an accusative case marker, even in the case of intransitive verbs. Whether this construction is to be counted as an instance of reduplication is mostly a terminological 
matter; other suitable labels may include verb doubling (Aboh 2006), or a cognate object construction. $^{8}$ Example (24) illustrates this construction with an intransitive verb, and example (25) contains a transitive verb, showing that both the nominalized copy of the verb and the direct object get accusative case markers.

(24) Jwanga kantayllatami kantarka, payka mana tushurkachu.

Jwan-ga kanta-y-lla-ta-mi kanta-rka, pay-ka mana tushu-rka-chu.

Juan-TOP sing-NZR-EXCL-ACC-MI sing-PST, he-TOP not dance-PST-NEG

'Juan only SANG, he didn't dance'

(25) Rusaka jura aswataka mana maliyllataka malirkachu upyaytami upyarka.

Rusa-ka jura aswa-ta-ka mana mali-y-lla-ta-ka mali-rka-chu, Rosa-TOP corn beer-ACC-TOP not taste-NZR-EXCL-ACC-TOP taste-PST-NEG, upya-y-ta-mi upya-rka.

drink-NZR-ACC-MI drink-PST

'Rosa didn't only TASTE the corn beer, she also DRANK it.'

Example (25) in addition shows that verbal reduplication may also occurs without the presence of -lla on the verb. Just as for adjectives, there seems to be a focus meaning connected to it. Additional examples are given in (26) and (27).

(26) a. Wambraka tushuytami tushurka.

Wambra-ka tushu-y-ta-mi tushu-rka.

boy/girl-TOP dance-NZR-ACC-MI dance-PST

'The boy/girl DANCED' [context: instead of other things that (s)he was expected to do, (s)he danced]

b. Tamyaytami tamyarka.

Tamya-y-ta-mi tamya-rka.

rain-NZR-ACC-MI rain-PST

'It RAINED' [context: one expected it to drizzle, but it didn't. It rained.]

(27) a. Q: Jwanga arrustaka yanurkachu?

Q: Jwan-ga arrus-ta-ka yanu-rka-chu?

Juan-TOP rice-ACC-TOP cook-PST-Q

'Did Juan cook the rice?'

b. A: Mana, payka arrusta yanurkachu. Mikuytami mikurka.

A: Mana, pay-ka arrus-ta yanu-rka-chu. Miku-y-ta-mi miku-rka. no, he-TOP rice-TOP cook-PST-NEG eat-NZR-ACC-MI eat-PST

'No, he didn't cook the rice. He ATE the rice'

${ }^{8} \mathrm{I}$ am indebted to Lauren Winans for suggesting the label 'cognate object' for this construction. 
One aspect in which the verbal reduplication strategy differs from the adjectival reduplication strategy, is that in the former but not the latter material may intervene. This is illustrated for -lla in (28a), in which an adverb intervenes between the reduplicated verb copies. Other positions of the adverb are possible as well, with the adverb appearing before the verbs being the most neutral option. The sentence in (28a) is equally grammatical but in the opinion of the consultant has slightly more emphasis on 'yesterday'. Example (28b) shows intervention of a direct object in reduplication with the suffix -pash. This word order was uttered spontaneously by the consultant, but the variant with adjacent verb copies was judged equally grammatical.

a. Jwanga kantayllatami kaynaka kantarka.

Jwan-ga kanta-y-lla-ta-mi kayna-ka kanta-rka.

Juan-TOP sing-NZR-EXCL-ACC-MI yesterday-TOP sing-PST

'Juan only SANG yesterday'

b. Maryaka kilkaytapash libruta kilkarka.

Marya-ka kilka-y-ta-pash libru-ta kilka-rka.

Maria-TOP write-NZR-ACC-ADD book-ACC write-PST

'Maria also wrote a book' [in addition to reading one]

Doubling strategies have been reported as a verbal focus strategy in other languages, in particular African languages (Aboh 2004, 2006 and references in there). In the Kwa language group, one verb focus strategy consists of preposing a "nominalized reduplicated verbal gerund" (Aboh 2004:12), which is superficially quite similar to Quichua. There are, however, important syntactic differences. A common analysis of the verb doubling in the relevant African languages is that it is a regular instance of focus movement, but with both copies pronounced. In Quichua the copied verb does not move consistently to the left periphery, but typically remains close to the original verb, more similar to the position of a regular direct object. A more detailed syntactic analysis of this phenomenon is required, which I leave to future research.

In a similar vein to the case of adjectives, I suggest that verbal reduplication is a different instance of structural association, influenced by polysemy of -lla in the verbal domain. Because both for adjectives and verbs, it was found that the reduplication carries some focus meaning by itself, the findings are not incompatible with an analysis in which the reduplication itself is a focus-marking strategy that generates alternatives, and -lla merely attaches and applies to the available alternatives. An analysis along these lines is not in conflict with my proposal, but my proposal has the advantage of maintaining a uniform analysis of -lla with the conclusions reached for nominal associates as discussed in section 3.

\section{Conclusion}

The main empirical conclusions are summarized in Table 1.

This table is not exhaustive, for example I have not talked about -lla taking scope over an entire VP. I have not included examples on VP-scoping 'only', because the data are a little less clear than those summarized in Table 1. Based on the preliminary conclusions I have 
Table 1: Behavior of -lla

\begin{tabular}{|l|l|l|}
\hline category of X & meaning of X-lla & way to express 'only $[\mathrm{X}]_{F}$ ' \\
\hline noun & only & X-lla \\
complex NP & only & $\mathrm{X}_{0}$-lla (i.e. -lla on head noun) \\
adjective / adverb & weakening meaning & X-lla X \\
verb & 'just' & X-y-lla-ta X \\
\hline
\end{tabular}

gotten so far, it seems that there is some variation with respect to the position of -lla within the VP when its semantic scope is formed by that VP. This is not entirely unexpected, since we see something similar in the parallel case of $-m i$ in question-answer pairs. A question like 'What happened?' requires an answer in which the entire VP is new information, and in Quichua it turns out that in a felicitous answer to that question, - $m i$ can attach to different constituents within the VP. This suggests a further parallel between the distributions of -lla and $-m i$ beyond what was discussed in section 3.1.

I proposed an account of structural association for -lla that is independent of the marker - $m i$. Although $-m i$ is used to mark new information in contexts of question-answer pairs and contrastive focus, I argued that $-m i$ is not responsible for introducing alternatives to AS-particles. This means - mi plays some but not all roles that are typically expected for a 'focus marker' reasoning from an English perspective. On the other hand, in our study of adjectives and verbs in section 4 we found that a special reduplicative construction used to associate AS-particles with their scope was also a way to indicate contrastive focus. Hence, at least for adjectives and verbs, the connection between new information focus in questionanswer pairs, and AS-particles in Quichua lies not in the marker -mi, but in the shared morphosyntactic constructions of reduplication. It is important to remember, though, that reduplication is the only way to associate AS-particles with their adjectival or verbal scope, but reduplication is only one possible (perhaps more emphatic) way to express contrastive focus with an adjective or a verb. Therefore further research to enhance our understanding of contrastive focus in Quichua is needed in order to appreciate the full theoretical consequences of these findings.

Going back to cases of nominal associates of AS-particles, there is still a non-uniform paradigm of focus marking in Quichua: - $m i$ marks focus in question-answer pairs, but does not mark the argument of AS-particles. This non-uniform focus marking in Quichua may be problematic for theoretical accounts that have attempted to reduce the role of focus in question-answer congruence to the introduction of alternatives. Zimmermann and Onea (2011), for instance, argue that alternatives ("privileged possible worlds" in their terminology) and the answer space of wh-questions are "sides of the same coin" (p. 1654). For example, the alternatives generated by the free focus in (29a) yield a set of propositions $\{$ Mary went to Paris, Linda went to Paris, Fred went to Paris, ... \}. This set is equal to the denotation of the question, under the common view that a question denotes the set of possible answers.

a. PETER went to Paris.

(Zimmermann and Onea 2011)

b. Who went to Paris?

A second theoretical consequence of the current work is the conceptual link between eviden- 
tiality and focus that Quechua researchers have assumed was exemplified by the dual role of - $m i$. We now have a better view on the focus uses of $-m i$, and this can lead to a more refined view on how focus and evidentiality are related.

Let me finish by indicating directions for future research. Besides the theoretical investigations just mentioned, it is clear that many of the empirical facts reported in this paper need further elaboration. I am thinking in particular of investigating more precisely the syntactic behavior of the adjectival and verbal reduplication paradigms discussed in section 4. This work may be aided by what is known of verb doubling focus strategies in African and other languages as discussed above; this may give rise to valuable cross-linguistic results on the morphosyntax of focus marking. In addition, and from a very different perspective, this work could be related to contemporary syntactic research on focus and topic marking, which has already been applied to Southern Quechua in Sánchez (2010). How her theory applies to Imbabura Quichua, and to the novel data reported in this paper in particular, needs to be seen, but these suggestions for future research together promise to be an exciting research program that applies contemporary semantic and syntactic theories to the cross-linguistic study of focus.

\section{References}

Aboh, Enoch Oladé, 2004. Focus constructions across Kwa. In Chege Githiora, Heather Littlefield, and Victor Manfredi, eds., Kinyĩra njĩra! Step firmly on the pathway!, 7-22. Trenton, NJ: Africa World Press.

Aboh, Enoch Oladé, 2006. When verbal predicates go fronting. ZAS Papers in Linguistics 46:21-48.

Aboh, Enoch Oladé, Hartmann, Katharina, and Zimmermann, Malte, eds., 2007. Focus Strategies in African Languages. Berlin: Mouton de Gruyter.

Adelaar, Willem F. H., 2004. The Languages of the Andes. Cambridge: Cambridge University Press. With the collaboration of Pieter C. Muysken.

Barchas-Lichtenstein, Jena, Galant, Michael, Kapitonov, Ivan, Korotkova, Natasha, Kim, Yun J., Martin, Cansada, Munro, Pam, and Tellings, Jos L., 2013. Field notes on Imbabura Quichua 2012-2013. Linguistics Field Methods Class, UCLA.

Beaver, David, Clark, Brady Zack, Flemming, Edward, Jaeger, T. Florian, and Wolters, Maria, 2007. When semantics meets phonetics: acoustical studies of Second-Occurrence Focus. Language 83(2):245-276.

Cinque, Guglielmo, 1999. Adverbs and Functional Heads: A Cross-linguistic Perspective. Oxford: Oxford University Press.

Cole, Peter, 1982. Imbabura Quechua. Amsterdam: North-Holland Publishing Company.

Cole, Peter and Hermon, Gabriella, 1981. Subjecthood and Islandhood: Evidence from Quechua. Linguistic Inquiry 12(1):1-30. 
Faller, Martina, 2002. Semantics and Pragmatics of Evidentials in Cuzco Quechua. Ph.D. thesis, Stanford.

Faller, Martina, 2003. The evidential and validational licensing conditions for the Cusco Quechua enclitic -mi. Belgian Journal of Linguistics 16:7-21.

Göksel, Aslı and Özsoy, A. Sumru, 2003. dA: a focus/topic associated clitic in Turkish. Lingua 113:1143-1167.

Gómez-Rendón, Jorge, 2006. Interpersonal aspects of evidentiality in Ecuadorian Quechua. ACLC Working Papers 1:37-50.

Gómez-Rendón, Jorge, 2008. Typological and social constraints on language contact: Amerindian languages in contact with Spanish (vol. 1), chapter 6, 169-193. Utrecht: LOT. PhD dissertation, University of Amsterdam.

Hartmann, Katharina and Zimmermann, Malte, 2007. Exhaustivity marking in Hausa: a reanalysis of the particle nee/cee. In Enoch Oladé Aboh, Katharina Hartmann, and Malte Zimmermann, eds., Focus Strategies in African Languages, 241-263. Berlin: Mouton de Gruyter.

Hartmann, Katharina and Zimmermann, Malte, 2008. Not only 'only', but 'too', too: alternative-sensitive particles in Bura. In Alte Grønn, ed., Proceedings of Sinn und Bedeutung 12, 196-211. Oslo: ILOS.

Hartmann, Katharina and Zimmermann, Malte, 2012. Focus marking in Bura: semantic uniformity matches syntactic heterogeneity. Natural Language and Linguistic Theory 30:1061-1108.

Herburger, Elena, 2000. What counts. Focus and quantification. Cambridge, MA: MIT Press.

Hermon, Gabriella, 2001. Non-Canonically Marked A/S in Imbabura Quechua. In R.M.W. Dixon, A.Y. Aikhenvald, and Masayuki Onishi, eds., Non-Canonical Marking of Subjects and Objects, 149-176. Amsterdam and Philadelphia: John Benjamins.

Jake, Januce and Chuquín, Carmen, 1979. Validation suffixes in Imbabura Quechua. In Proceedings of the Chicago Linguistic Society 15, 172-184. University of Chicago.

Kim, Yun J., 2013. Intonational Phonology of Quichua. Ms., UCLA.

König, Ekkehard, 1991. The Meaning of Focus Particles. A Comparative Perspective. London: Routledge.

Kwon, Iksoo, 2012. One -mi: an Evidential, Epistemic Modal, and Focus Marker in Imbabura Quechua. Survey Reports, Survey of California and Other Indian Languages, University of California, Berkeley.

Muntendam, Antje, 2012. Bilingual intonation: a case study of Andean Spanish. L2 Prosody Workshop. 
Muysken, Pieter, 1995. Focus in Quechua. In K. Kiss, ed., Discourse configurational languages, 375-393. Oxford: Oxford University Press.

Nuckolls, Janis B., 1993. The semantics of certainty in Quechua and its implications for a cultural epistemology. Language in Society 22:235-255.

Olbertz, Hella, 2008. Spanish expressions of direct evidential and affirmative validation? Searching for a linguistic reflex of Quechua -mi in Rural Ecuadorian Highland Spanish. In Carla Vergaro, ed., Dynamics of language contact in the twenty-first century, 111-131. Perugia: Guerra.

Otoguro, Ryo, 2003. Focus clitics and discourse information spreading. In Miriam Butt and Tracy Holloway King, eds., Proceedings of the LFG03 Conference, 367-386. CSLI Publications.

Reinhart, Tanya, 2004. The Processing Cost of Reference Set Computation: Acquisition of Stress Shift and Focus. Language Acquisition 12(2):109-155.

Rooth, Mats, 1992. A theory of focus interpretation. Natural Language Semantics 1:75-116.

Sánchez, Liliana, 2010. The Morphology and Syntax of Topic and Focus. Minimalist inquiries in the Quechua periphery. Amsterdam: John Benjamins.

Speas, Peggy, 2008. On the Syntax and Semantics of Evidentials. Language and Linguistic Compass 2/5:940-965.

Tellings, Jos L., 2014a. Field notes on Imbabura Quichua, 2013-2014. UCLA.

Tellings, Jos L., 2014b. Intensifiers in Imbabura Quichua. Talk at SULA 8, Vancouver, BC, May 2014.

Weber, David John, 1989. A Grammar of Huallaga (Huánuco) Quechua. Berkeley and Los Angeles: University of California Press.

Willgohs, Beatrix and Farrell, Patrick, 2009. Case and Grammatical functions in Imbabura Quechua: an LFG approach. In Miriam Butt and Tracy Holloway King, eds., Proceedings of the LFG09 Conference, 623-643. Stanford: CSLI Publications.

Zimmermann, Malte and Onea, Edgar, 2011. Focus marking and focus interpretation. Lingua 121:1651-1670. 